\title{
Cholinergic component in the human pancreatic secretory response to intraintestinal oleate
}

\author{
J E VALENZUELA, C B LAMERS, I M MODLIN, AND J H WALSH \\ From the Gastroenterology Section, University of Southern California, School of Medicine, and VA \\ Wadsworth, Los Angeles, California
}

SUMMARY To determine the role of cholinergic reflexes on pancreatic secretory response to food, we studied the effect of atropine on amylase secretion in response to the octapeptide of cholecystokinin (CCK8) and to intraintestinal oleate. Four studies were done in six healthy volunteers. The duodenal content was aspirated by a double lumen tube while synthetic secretin $(41 \mathrm{pmol} / \mathrm{kg} / \mathrm{h})$ was infused as a background in all the studies. Graded doses of CCK8 IV or 0.42 $\mathrm{M}$ oleate $\mathrm{pH} 9.4$ at $25 \mathrm{ml} / \mathrm{h}$ into the intestine with and without atropine $1.8 \mathrm{mg}$ were given on different days. CCK-like immunoreactivity (LI) in the plasma was measured by RIA during the intraintestinal oleate studies. CCK8 stimulated pancreatic enzyme secretion in a dose related fashion, an effect that was not modified by atropine. Intraintestinal oleate also stimulated pancreatic secretion and increased the CCK-LI in the plasma. Atropine significantly $(\mathrm{p}<0.05)$ decreased the pancreatic enzyme secretion before and during intraintestinal oleate, without effect on the CCK-LI levels. We conclude: (1) that the effect of exogenous CCK on pancreatic secretion of enzymes is not affected by atropine; (2) intraintestinal oleate stimulates pancreatic enzyme secretion significantly by an atropine-sensitive mechanism; (3) probably the atropine effect is a blockade of a cholinergic enteropancreatic reflex.

Although it is generally accepted that gastrointestinal hormones play a predominant role in the pancreatic secretory response to intraintestinal stimulants, ${ }^{1}$ observations both in $\operatorname{dogs}^{2-5}$ and $\operatorname{man}^{6}$ show that atropine and vagotomy reduce pancreatic enzyme secretion in basal conditions and during perfusion of food digestion products into the intestine. The atropine and vagotomy effect could be interpreted as either due to decreased sensitivity of the pancreas to cholecystokinin (CCK) stimulation or to an impaired release of CCK from the intestinal mucosa. ${ }^{34}$ Solomon and Grossman, more recently, based on studies on dog transplanted pancreas, proposed that atropine and vagotomy effects may result from the interruption of an enteropancreatic reflex. ${ }^{7}$ A similar study in humans cannot be done. The development of a radioimmunoassay for CCK8, however, that permits correlation of enzyme secretion with increments in CCK-like-immunoreactivity (CCK-LI) in plasma, ${ }^{8}$

Address for correspondence: Dr J E Valenzuela. Section of Gastroenterology, USC School of Medicine, 2025 Zonal Avenue, Los Angeles, CA 90033. USA. Received for publication 19 November 1982 prompted us to re-examine in humans the effect of atropine on: (1) the pancreatic secretory response to exogenous CCK and intraintestinal perfusion of oleate and, (2) the release of endogenous CCK during oleate perfusion into the intestine.

We found that atropine did not have significant effect on the pancreatic secretory response to exogenous CCK. Moreover, atropine did not affect the release of endogenous CCK during intraintestinal oleate infusion, although the pancreatic secretory response, as expected, was depressed. Our findings suggested that atropine blocked a cholinergic mechanism similar to the enteropancreatic reflex described by Solomon and Grossman in dogs. ${ }^{7}$

Methods

SUBJECTS

Six healthy human volunteers (five men and one woman) ages 21 to 32 years were studied. The protocol was approved by the LAC-USC Human Research Committee Center (No. 01484) and each subject signed an informed consent. 
EXPERIMENTAL DESIGN

After an overnight fast, the subjects swallowed a rubber double-lumen tube. The tip, was positioned under fluoroscope guidance in the intestine at the level of the ligament of Treitz and the duodenal openings were located in the second and third portion of the duodenum. A small polyvinyl tube was attached to the rubber tube and was used to perfuse phenol red $30 \mu \mathrm{g} / \mathrm{ml}$ at $2 \mathrm{ml} / \mathrm{min} 5 \mathrm{~cm}$ distal to the pylorus. The gastric and duodenal contents were aspirated continuously at $-5 \mathrm{~mm} \mathrm{Hg}$ with a pump. The gastric and duodenal aspirates were pooled in 15-minute samples.

Synthetic secretin $41 \mathrm{pmol} / \mathrm{kg} / \mathrm{h}$ (provided by Squibb and Sons, Princeton, New Jersey) was infused into a peripheral vein as a background throughout all the studies. Four studies were done on different days in a randomised order.

\section{STUDY 1}

On one day, after 30 minutes of secretin infusion, CCK8 (Kinevac, Sincalide, Squibb and Sons) in doses of $8 \cdot 8,26.2$ and $78.6 \mathrm{pmol} / \mathrm{kg} / \mathrm{h}$ (equivalent to 10,30 and $90 \mathrm{ng} / \mathrm{kg} / \mathrm{h}$ of CCK8) was sequentially added to the infusion. The lowest dose was infused over 45 minutes and the subsequent doses over 30 minutes each.

\section{STUDY 2}

Study 1 was repeated on another day but this time $1.8 \mathrm{mg}$ atropine sulphate was given, $0.9 \mathrm{mg}$ as rapid intravenous injection and $0.9 \mathrm{mg}$ subcutaneously, at the beginning of the secretin infusion.

For the next two studies, a second small polyvinyl tube was attached so that its tip was $6 \mathrm{~cm}$ distal to the tip of the rubber tube.

\section{STUDY 3}

The assembly was swallowed and positioned into the intestine as previously. At the time of the beginning of the secretin infusion, the intestine was perfused through the fourth tube with $0.15 \mathrm{M}$ saline solution at $25 \mathrm{ml} / \mathrm{h}$. At the end of 30 minutes of saline infusion into the intestine, $50 \mathrm{ml} 0.42 \mathrm{M}$ sodium oleate, $300 \mathrm{~m} \mathrm{Osm} / \mathrm{kg}$ was perfused at $25 \mathrm{ml} / \mathrm{h}$ over two hours. Perfusates were prepared on the day of each experiment by dissolving sodium oleate (Sigma Chemical Co, St Louis, MO) in an aqueous solution of $\mathrm{NaOH}, \mathrm{pH}$ 9.2-9.4 required for adequate dispersion. ${ }^{9}$ Duodenal aspirate was collected as in the previous studies. Occasionally some oleate refluxed to the duodenum noted by cloudiness of the aspirate. Whenever this happened, the samples were centrifuged and the supernatant discarded to avoid interference of oleate with enzyme determination.

\section{STUDY 4}

Study 3 was repeated but this time the subjects also received $1.8 \mathrm{mg}$ atropine, half the dose intravenously and the other half subcutaneously.

During the oleate infusion studies, $6 \mathrm{ml}$ of blood was taken from a peripheral vein every 15 minutes from the beginning of the secretin infusion. The plasma was quickly separated, frozen and stored at $-20^{\circ} \mathrm{C}$ until radioimmunoassay determinations for CCK-LI were done.

AMYLASE ASSAY

The volume of duodenal aspirate was measured to the nearest $0.1 \mathrm{ml}$. Amylase concentration was measured by a modified automated saccharogenic method. ${ }^{10}$ Phenol red concentration in the duodenal aspirate was measured by comparing the absorbance of the aspirate with a standard at $530 \mathrm{~nm}$. Amylase output in the aspirate was corrected for the recovery of phenol red which averaged $70 \%$. The amount of phenol red recovered in the gastric aspirate averaged $7 \%$.

RADIOIMMUNOASSAY OF CHOLECYSTOKININ-LIKE IMMUNOREACTIVITY

CCK-LI was measured by radioimmunoassay as previously described. ${ }^{8}$ Briefly, CCK-LI was concentrated by affinity chromatography, characterised by gel filtration and by radioimmunoassay with two antibodies, 5135 and 1611 with different specificity for CCK and gastrin. The antibody, 5135, was raised against synthetic non-sulfated octapeptide of CCK (CCK-8-NS, Squibb) conjugated to bovine serum albumin. This antiserum bounds all known molecular forms of CCK and gastrin. The inhibition dose 50 (ID50) was similar for synthetic nonsulfated and sulfated forms of CCK-8, gastrin-34 gastrin-17, and gastrin-14; between 3 and 4 pmol-ml incubation mixture. The binding to $99 \%$ pure porcine CCK33 (V. Mutt, Karolinska Institute, Stockholm) was $50 \%$ lower than that to CCK8. Non-sulfated CCK8 was labelled with ${ }^{125}$ I using chloramine-T and purified by DE 11 anion exchange chromatography. Synthetic sulfated CCK8 was used as standard. The samples were also measured by gastrin radioimmunoassay using an antibody (1611) that binds all known molecular forms of gastrin and has less than $3 \%$ cross-reactivity with CCK8 and CCK33. Total immunoreactivity measured with antibody 5135 was corrected by subtraction of specific gastrin immunoreactivity measured with antibody 1611 for estimation of CCK immunoreactivity. Molecular forms of CCK were not further characterised in the present study.

Exogenous CCK8 administered in similar conditions to those of this study, caused graded 
increments in amylase secretion and a positive correlation was observed between amylase output and CCK-LI increments in the plasma. ${ }^{8}$

\section{CALCULATIONS}

The amylase values obtained during the last 15 minutes of secretin infusion alone were averaged and values with and without atropine were compared. For the CCK infusion studies, the amylase values during the last period were averaged and values with and without atropine were compared. For the oleate studies the amylase values obtained during oleate infusion were averaged for 30 minute periods and values with and without atropine were compared. The plasma CCK-LI increments observed during oleate infusion in each subject were grouped for 30 minutes and the means compared when atropine was and was not administered. Statistical analysis was by Wilcoxon's signed rank test for paired values.

\section{Results}

Amylase secretion during secretin alone was significantly decreased after pretreatment with atropine, $(17.8 \pm 5.4 \mathrm{KU} / 15 \mathrm{~min}$ vs $7.4 \pm 0.9 \mathrm{KU} / 15 \mathrm{~min}$, $\mathrm{p}<0.05$ ) (Fig. 1). The infusion of CCK8 caused a marked increase in the amylase output and reached maximal levels during the infusion of CCK8 78.6 $\mathrm{pmol} / \mathrm{kg} / \mathrm{h}$. Although pretreatment with atropine caused less amylase output particularly during infusion of 8.8 and $78.6 \mathrm{pmol} / \mathrm{kg} / \mathrm{h}$ of CCK8, the difference in amylase output during CCK infusion with and without atropine was approximately the same as the effect on basal. Expressed in other

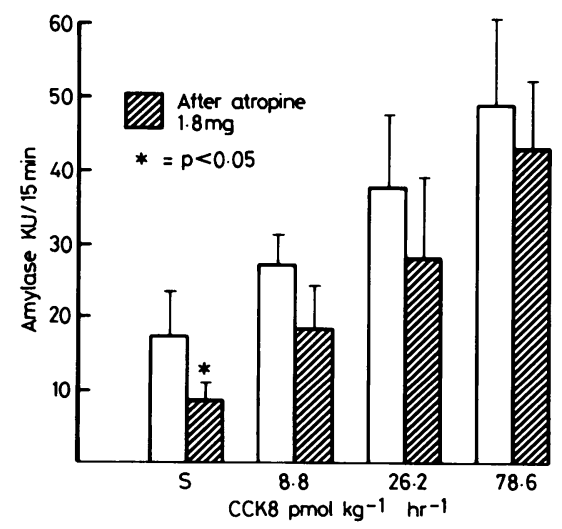

Fig. 1 Effect of atropine on amylase output in duodenal aspirate during infusion of graded doses of CCK8 $(n=6)$. Bars represent mean \pm 1 SEM.

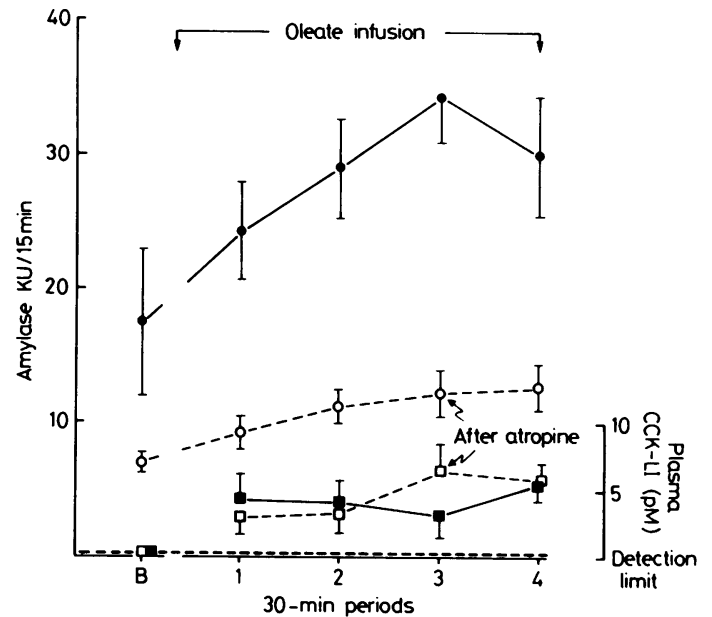

Fig. 2 Mean ( $\pm S E M)$ amylase and plasma CCK-LI during intraintestinal perfusion of oleate $(0.42 \mathrm{M}$ at 25 $\mathrm{ml} / \mathrm{h})(\bullet)$ amylase without atropine; $(\circ)$ amylase after atropine; (घ) CCK-LI without atropine; (ㅁ) CCK-LI after atropine. Detection limit was below $0 \cdot 2$ pM.

terms, the increments in amylase output over basal during 10,30 and $90 \mathrm{ng} / \mathrm{kg} / \mathrm{h}$ CCK8 respectively, were not significantly different from the increments during the same doses of CCK8 observed after atropine $(9.5$ vs $9 \cdot 4,20.4$ vs $18 \cdot 6,31.6$ vs $34.4 \mathrm{KU} / 15$ $\min$ ).

The infusion of oleate into the intestine produced a significant increase in amylase secretion (Fig. 2). The mean amylase output observed during the two hours of oleate infusion $(27.9 \pm 0.4 \mathrm{KU} / 15 \mathrm{~min})$ was similar to that obtained during the infusion of CCK8 at a dose of $8.8 \mathrm{pmol} / \mathrm{kg} / \mathrm{h}(26.7 \pm 0.5 \mathrm{KU} / 15 \mathrm{~min})$. Pretreatment with atropine caused a significant decrease $(p<0.01)$ in the amylase secretion during intraintestinal oleate. The mean amylase output after atropine during the two hours of oleate infusion $(11.4 \pm 1.8 \mathrm{KU} / 15 \mathrm{~min})$ was approximately $40 \%$ of the response observed without atropine. After atropine, however, oleate perfusion caused a modest but significant increase in amylase output $(p<0.05)$ when compared to pre-oleate values (Fig. 2).

With the present radioimmunoassay, no detectable CCK-LI could be measured in fasting conditions. Intraintestinal oleate caused a measurable increase in CCK-LI in the plasma, while no change was found using the gastrin specific antibody 1611 . Pretreatment with atropine did not significantly modify the increment in CCK-LI measured with antibody 5135 , nor change the results with antibody 1611 (Fig. 2). 


\section{Discussion}

The transfer of food from the stomach to the intestine evokes a prompt secretory response of pancreatic enzymes. This response seems to be mediated by neural and hormonal mechanisms arising from the duodenal mucosa, activated by products of fat and protein digestion. While our understanding of the hormonal mechanism has improved as measurement of the peptides has become available, the neural mechanisms responsible for stimulation have been investigated indirectly by observations of the effects of atropine and vagotomy.

Studies in dogs ${ }^{2-5}$ and in humans ${ }^{6}$ have shown that both atropine and vagotomy decrease the volume and output of enzymes of both basal secretion and the response to infusion of a mixture of essential amino acids into the intestine ${ }^{356}$ and oleate. ${ }^{5}$ These results have been interpreted as evidence that: (1) there is a cholinergic tone that conditions the pancreatic secretory response to CCK and other gastrointestinal peptides; (2) the release of CCK as well as of those peptides by the intestinal mucosa is cholinergically dependent; or (3) that atropine and vagotomy interrupt or block a cholinergic 'enteropancreatic reflex'?

The first possibility does not seem to be supported by our results or those of Malagelada et al ${ }^{6}$ which showed that vagotomy and atropine decreased insignificantly the enzyme secretion to graded doses of exogenous CCK. The second possibility is not compatible with the present observation as the release of CCK-LI was not decreased significantly by pretreatment with atropine while amylase output was significantly inhibited. In fact the increment of CCK-LI by infusion of intraintestinal oleate was not affected by atropine but the amylase secretion was approximately $40 \%$ of the output observed during the infusion of oleate without atropine. After atropine, oleate into the intestine still caused a small but significant increment of amylase secretion above pre-oleate levels. This increase in amylase output may represent a response to the increment in the plasma CCK that is not affected by atropine. Indeed, this increment in amylase output (approximately $4 \mathrm{KU} / 15 \mathrm{~min}$ ) is similar to that observed in response to doses of exogenous CCK8 which caused comparable increment in plasma CCK- $\mathrm{LI}^{8}$ to those observed during intraintestinal oleate in the present study.

$\mathrm{We}^{8}$ and others ${ }^{11}$ have found that most of the apparent CCK-LI detected with antibody 5135 in the basal state in man was because of gastrin or non-specific plasma effects that could not be removed by immuno-absorption. The increase in immunoreactivity, however, detected after intraintestinal oleate was due chiefly to increase in a peptide that resembled CCK8 on Sephadex G50) gel filtration. Finally, the increase in CCK-LI measured in the present study was similar in magnitude to those found after concentration of plasma by affinity chromatography by us ${ }^{x}$ and by Calam et al. ${ }^{11}$

Regarding the release of other peptides by intraintestinal oleate, recent studies have shown that although oleate may release secretin in man $^{12}$ this effect is not affected by atropine. Although similar evidence for VIP is not available, this peptide is a very weak stimulant of pancreatic enzyme secretion and it seems unlikely that the inhibition in amylase output could be due to suppressed release of VIP.

As bile salts release secretin from the duodenum. mention should be made of the possibility that the decreased amylase output after atropine could be because of impairment of gall bladder emptying. This possibility is unlikely first because secretin alone is a weak stimulant of pancreatic enzyme secretion, and secondly because the subjects in this study received secretin continuously as a background which most likely would have minimised changes in secretin levels produced by gall bladder contraction.

Indirectly our results seem to provide evidence that atropine blocked a cholinergic mechanism, possibly the 'enteropancreatic reflex'. This concept has been supported solidly by observations in the transplanted pancreas in the dog. In this preparation, which interrupts the nerve connections between the intestine and the pancreas, atropine did not affect the secretory response of the transplanted pancreas to intraintestinal stimuli as it did in the non-transplanted pancreas, which retained its innervation. ${ }^{7}$ More recently, it was shown that tryptophan and oleate given intraduodenally in the dog had a shorter latency in the stimulation of amylase secretion, than intraportal CCK. Atropine and truncal vagotomy increased the latency suggesting that the early pancreatic enzyme response is mediated by a cholinergic vagal reflex.${ }^{13}$ Finally, we have shown in dogs that amylase output during intraintestinal oleate is significantly decreased by atropine without a similar effect on CCK-LI concentrations. ${ }^{14}$

Although atropine did not significantly modify the CCK effect on enzyme secretion, it significantly decreased the secretin effect on amylase secretion. Similar observations have been made in $\operatorname{dog}^{15}$ and $\operatorname{man}^{12} 16$ and suggest that the secretin receptors in the acinar cells are more dependent on cholinergic pathways than the CCK receptors.

In conclusion, atropine and vagotomy seem to decrease the pancreatic secretory response to intra- 
intestinal stimuli in man mainly by blockade of a cholinergic mechanism, probably the 'enteropancreatic reflex'. Also, this reflex seems to be responsible for as much as half the secretory response of the human pancreas to intraluminal food stuff. In addition, these results may offer an alternative possibility to understand the mechanism of steatorrhea in patients with diabetes and visceral neuropathy, particularly in those patients who do not respond to antibiotics. These patients may have and inadequate pancreatic secretory response to food similar to vagotomised patients. ${ }^{6}$

The authors wish to thank Georgette Buga for expert technical assistance and Alice Lozoya for typing the manuscript. This study was supported in part by a grant from the National Institute of Arthritis, Metabolism, and Digestive Diseases (AM 17294). Dr C B Lamers is supported by the Netherlands Organization for the Advancement of Pure Research (SWO), and in part by NIH Grant AM 17294.

\section{References}

1 Harper AA. Physiologic factors regulating pancreatic secretion. Gastroenterology 1959; 36: 386-91.

2 Thomas JE. Mechanism of action of pancreatic stimuli studied by means of atropine-like drugs. Am J Physiol 1964; 206: 124-8.

3 Konturek SJ. Tasler J, Obtulowicz W. Effect of atropine on pancreatic responses to endogenous and exogenous cholecystokinin. Dig Dis 1972; 17: 911-7.

4 Konturek SJ, Becker HD, Thompson JC. Effect of vagotomy on hormones stimulating pancreatic secretion. Arch Surg 1974; 108: 704-8.

5 Debas HT, Konturek SJ, Grossman MI. Effect of extragastric and truncal vagotomy on pancreatic secretion in the dog. Am J Physiol 1975; 228: 1172-7.

6 Malagelada JR, Go VLW, Summerskill WHJ. Altered pancreatic and biliary function after vagotomy and pyloroplasty. Gastroenterology 1974; 66: 22-7.

7 Solomon TE, Grossman MI. Effect of atropine and vagotomy on response of transplanted pancreas. $\mathrm{Am} \mathrm{J}$ Phvsiol 1979; 236: E186-90.

8 Walsh JH, Lamers CB, Valenzuela JE. CCK8-likeimmunoreactivity in human plasma. Gastroenterology 1982: 82: 438-44.

9 Meyer JH, Rayford SJ. Canine pancretic responses to intestinally perfused fat and products of fat digestion. Am J Physiol 1974; 226: 1178-87.

10 Matthews WS, Sterling RE, Boyd T, Flores P. Modified automated saccharogenic determination of serum and urinary amylase activity. Clin Chem 1973; 19: $1384-6$.

11 Calam J, Ellis A, Dockray GJ. Identification and measurement of molecular variants of cholecystokinin in duodenal mucosa and plasma. J Clin Invest 1982; 69: 218-25.

12 You CH, Rominger JM, Chey WY. Effect of atropine on the action and release of secretin in man. Am J Physiol 1982; 242: Gastrointest Liver Physiol 5: G608-11.

13 Singer MV, Solomon TE, Wood J, Grossman MI. Latency of pancreatic enzyme response to intraduodenal stimulants. Am J Physiol 1980; 238: Gastrointest Liver Physiol 1: G23-9.

14 Modlin IM, Hansky J, Singer M, Walsh JH. Evidence that the cholinergic enteropancreatic reflex may be independent of cholecystokinin release. Surgery 1979; 86: $352-61$.

15 Schmidt DN, Sarles H, Biedzinski TM, Devaux MA. Cholinergic secretory and inhibitory mechanisms in canine pancreatic secretion. Scand J Gastroenterol 1981; 16: 341-52.

16 Defilippi C, Solomon TE, Valenzuela JE. Pancreatic secretory response to sham feeding in humans. Digestion 1982; 23: 217-23. 